\title{
O COMPORTAMENTO SOCIALMENTE RESPONSÁVEL DAS EMPRESAS INFLUENCIA A DECISÃO DE COMPRA DO CONSUMIDOR?
}

\author{
DOES THE SOCIALLY RESPONSIBLE BEHAVIOR OF THE COMPANIES \\ INFLUENCE THE DECISION OF THE CONSUMER BUYING?
}

\section{Renata Céli Moreira da Silva}

\section{Hélène Bertrand}

\begin{abstract}
RESUMO
0 presente artigo buscou pesquisar a atitude e comportamento do consumidor em relação às empresas socialmente responsáveis. A pesquisa foi feita através de entrevistas com questionários. Foram entrevistados mestrandos de uma universidade do RJ. Os resultados mostraram que eles têm uma atitude positiva em relação à compra socialmente responsável, mas o seu comportamento ainda não envolve essa prática. Porém os consumidores não estão satisfeitos com seu modo de comprar e acham que as empresas poderiam disponibilizar mais informações sobre suas ações socialmente responsáveis.
\end{abstract}

Palavras-chave: Responsabilidade social. Atitude. Comportamento do consumidor.

\begin{abstract}
This article aims to identify the attitude and behavior of consumers concerning the Social Responsibility. This research was done through interviews with questionnaires. We interviewed postgraduation students from a university in RJ. The results showed that they have a positive attitude concerning socially responsible buying, however their behavior still does not involve the practice. But, consumers are not satisfied with the way they buy and think that companies should provide more information about their socially responsible actions.
\end{abstract}

Key-words: Social responsibility. Attitude. Consumer behavior. 


\section{INTRODUÇÃo}

Recentemente, o tema Responsabilidade Social Corporativa tem sido alvo de inúmeros debates, seja no campo da educação, solidariedade, meio ambiente, respeito aos funcionários, dentre outros pontos. Revistas, jornais, artigos científicos, palestras, dentre outras fontes de comunicação e informação têm tratado dessa questão, mostrando sua importância para a sociedade no mundo.

Além disso, pode-se dizer que mundialmente há uma pressão para que as organizações tenham práticas socialmente responsáveis, e essas pressões estão cada vez maiores (MOHR e WEBB, 2005).

Há países em que a consciência socialmente responsável está bastante desenvolvida.Dessa forma, um fator fundamental para a entrada de empresas nesses mercados é certificar que seu produto é correto, ou seja, que a empresa pratica a Responsabilidade Social.(CARVALHO e BARBIERI, 2007). Um exemplo é a Natura que pratica a Responsabilidade Social e isso constitui um fator na sua estratégia internacional, pois a coloca em uma posição favorável (SERRA et al. 2007).

Portanto, estudos têm sido feitos considerando a Responsabilidade Social Corporativa como fonte de vantagem competitiva para as empresas (MOTTA e ROSSI, 2003; LOMBARDI e BRITO, 2007; SERRA et al., 2007).

Cada vez mais as organizações têm feito relatórios de sustentabilidade e divulgado seus balanços sociais, e no Bovespa há o Índice de Sustentabilidade Empresarial, onde são divulgadas informações sobre Responsabilidade Social. Dessa forma, elas buscam comunicar aos stakeholders suas ações sociais, para que consigam conquistar uma boa imagem na sociedade.

Logo, atualmente almejar o lucro não é mais uma condição suficiente para a organização, é importante também que ela pratique a Responsabilidade Social, que ela leve em conta quais os impactos de suas ações dentro e fora do seu ambiente.

Muitos estudos têm sido feitos sobre o tema, porém há pouca abordagem do tema na ótica do consumidor, isto é, existem poucas pesquisas que tratam da percepção dos consumidores em relação ao comportamento socialmente responsável das empresas, se eles valorizam isso de fato e se isso influencia a sua intenção de compra de determinado produto (SEM e BHATTACHARYA, 2001; AUGER et al., 2003).

Apesar de haver poucos estudos sobre essa questão, ela é algo interessante a ser pesquisado, pois é importante saber se o comportamento socialmente responsável das empresas pode gerar uma intenção de compra positiva por parte dos consumidores, para então a empresa poder estabelecer um canal de comunicação mostrando aos seus clientes que suas práticas são corretas.

Portanto, o objetivo deste artigo é explorar se as práticas socialmente responsáveis das empresas influenciam o comportamento de compra dos consumidores, se os consumidores preferem comprar os produtos das empresas socialmente responsáveis. Esse estudo torna-se interessante, pois como a Responsabilidade Social está sendo muito discutida no Brasil e no mundo, é importante saber se isso está influenciando a decisão de compra do consumidor. 
Foram levantados alguns dos poucos estudos sobre a Responsabilidade Social na ótica do consumidor e esta pesquisa irá complementar esses estudos.

0 artigo é estruturado da seguinte forma: neste item é apresentada uma contextualização do assunto, a sua introdução. Na segunda etapa, é feita uma revisão da literatura sobre algumas definições a respeito do tema Responsabilidade Social e do comportamento do consumidor. $\mathrm{Na}$ terceira etapa, são mostrados alguns estudos existentes sobre esse tema na ótica do consumidor. Na quarta etapa, a metodologia da pesquisa é explicada, mostrando como foi feito o questionário, a coleta dos dados e o tratamento desses dados. Na quinta etapa, são mostrados os resultados e é feita a discussão desses resultados. E na última etapa, são feitas as considerações finais e são dadas algumas sugestões para futuras pesquisa.

\section{REVISÃO DA LITERATURA}

\section{A RESPONSABILIDADE SOCIAL CORPORATIVA (RSC)}

Schroeder e Schroeder (2004), em suas pesquisas, contaram sobre as raízes históricas da Responsabilidade Social Corporativa (RSC). Eles mostraram que anteriormente, o objetivo do mercado era o de prover o lucro e a condição humana e social eram colocadas em segundo plano, e com isso, quem era responsável pelo estabelecimento do bem estar social era o Estado. Contudo, o Estado possuía serviços de baixa qualidade e pouco recurso financeiro, oque gerou dificuldades em atender a sociedade. Dessa forma, houve uma busca por novas alternativas e, as empresas que eram vistas como grandes geradoras de riquezas materiais deveriam assumir uma maior parcela em relação à responsabilidade com a sociedade. Dessa maneira, surgiu a RSC. Drucker (1995) também afirmou sobre a ineficiência do Estado em promover o bem estar social e aborda que a partir dessa ineficiência, gerou-se essa preocupação com a RSC.

A RSC está em destaque atualmente. Segundo Faria e Sauerbronn (2008), o tema ganhou importância devido à crescente globalização, ao poder econômico e até político das grandes empresas, aos escândalos de organizações que ocorreram e vêm ocorrendo e às reações de ativistas e organizações. Calixto (2007) afirma que esse tema começou a ser debatido na década de 1960 nos países da Europa e nos Estados Unidos, sendo discutido a questão dos problemas sociais. E nos últimos anos o tema tem evoluído para incluir questões sobre ética e moral nas empresas. No Brasil, o início da discussão sobre as questões sociais também se deu a partir de 1960. Para Schommer e Rocha (2007) os debates sobre esse tema também ganharam importância durante essa época, contendo questões como o meio ambiente, o direito das mulheres e as desigualdades sociais.

Mas o que é Responsabilidade Social Corporativa? Existem muitas definições sobre esse tema na academia e no campo empresarial. E a definição de RSC ainda está em construção (ASHLEY, 2002).

De acordo com o Instituto Ethos de Empresas e Responsabilidade Social, a RSC é "a forma de gestão que se define pela relação ética e transparente da empresa com todos os públicos com os quais se relaciona e pelo estabelecimento de metas empresariais compatíveis com o desenvolvimento sustentável da sociedade, preservando recursos ambientais e culturais para as gerações futuras, respeitando a diversidade e promovendo a redução das desigualdades sociais". E os negócios se desenvolvem melhor quando são feitos de forma socialmente responsável, pois a sociedade fica mais saudável, melhor desenvolvida. (BRONN e VRIONI, 2001). 
Para os autores McWilliams e Siegel (2001), a RSC representa um conjunto de ações que deve estar além de cumprir somente as obrigações legais e os interesses básicos da empresa. As organizações devem também promover ganhos para a sociedade.

Para Srour (1998), a empresa socialmente responsável deve realizar ações para contribuir para o desenvolvimento da sociedade. Essas ações podem ser projetos que aumentem o bem estar, que contribuam para a preservação do meio ambiente, que melhorem o ambiente de trabalho para os funcionários, e também podem ser investimentos em tecnologia para melhorar processos e produtos para assim satisfazer seus clientes. Ashley (2002) aborda a RSC como um compromisso da empresa com a sociedade, através de atos e atitudes que a afetem de forma positiva. A organização deve assumir obrigações de caráter moral, além daquelas estabelecidas na lei, para que assim, a empresa contribua para o desenvolvimento sustentável da população. Ou seja, a RSC constitui em ações que ajudem na melhoria da qualidade de vida das pessoas. Ashley (2002) também mostrou os vetores da responsabilidade social, que são: apoio ao desenvolvimento da comunidade em que atua, preservação do meio ambiente, investimento no bem-estar e no ambiente de trabalho dos funcionários, transparência na comunicação, gerar retorno aos acionistas, ter sinergia com os parceiros e satisfazer os clientes e consumidores.

Pereira e Campos Filho (2007) fizeram uma proposta de um modelo de RSC e esse modelo pode ser utilizado para melhor entender a RSC. O modelo possui três dimensões: a econômica, a institucional e a ética. A dimensão econômica diz respeito à maximização dos lucros para os acionistas, que é um dos públicos que a empresa se relaciona. A dimensão institucional corresponde a ações sociais e responsabilidade sobre tomadas de decisão, que podem beneficiar os envolvidos e a empresa. A dimensão ética diz respeito às obrigações éticas das organizações, ter padrões e ideais éticos.

Schommer e Rocha (2007) fizeram um estudo para mostrar a evolução da prática da RSC no Brasil. Segundo os autores, existiram três ondas dessa prática no país. A primeira onda foi a filantropia. Nessa onda, as empresas realizavam ações sociais externas, geralmente através de doações, e essas ações muitas vezes não estavam vinculadas com a atividade principal da empresa, era uma ação somente de caridade. Ou seja, era uma forma de assistencialismo. A segunda onda foi caracterizada pelo investimento social privado, que era o repasse de recursos privados para projetos de interesse público. Esse repasse era feito de maneira planejada, era monitorado e podia ou não estar ligado à atividade principal da empresa. A terceira onda considera a gestão da RSC como parte da sua estratégia, ela é relacionada às atividades da empresa. Dessa forma, as organizações definem suas metas com objetivos que contemplam dimensões econômicas, sociais e ambientais.

Após saber o significado de RSC, pode-se ver que a organização tem um grande relacionamento com a sociedade, já que uma das suas práticas sociais deve ser com a sociedade. Portanto, é importante que ela divulgue informações sobre suas ações responsáveis para que a população possa ter esse conhecimento. Dufloth e Bellumat (2005) defendem que a disseminação dessas informações pode fortalecer os resultados sociais pretendidos pela empresa. Essa disseminação de informações pode ser útil para mostrar aos consumidores o que sua empresa está fazendo e com isso, pode fazer com que a pessoa seja um cliente potencial, se ela se interessar por esses assuntos sociais.

\section{O COMPORTAMENTO DO CONSUMIDOR}

Como o presente artigo vai abordar a RSC na ótica do consumidor, é importante conhecer um 
pouco a respeito do comportamento do consumidor. De acordo com Solomon (2002), os estudos do comportamento do consumidor são amplos, englobando como as pessoas selecionam, compram, usam os produtos ou serviços para satisfazerem seus desejos e necessidades. Desde a decisão de comprar até o uso que os consumidores fazem de produtos ou serviços são muito importantes para entender o comportamento do consumidor e precisam ser pesquisadas pelos profissionais de marketing (SEMENIK e BAMOSSY, 1996).

Segundo Kotler (2000), o processo de decisão de compra do consumidor engloba as seguintes etapas: reconhecimento da necessidade, busca de informação, avaliação das alternativas, decisão de compra e comportamento pós-compra. Para Peter e Olson (2005) os estágios do processo de decisão do consumidor são: reconhecimento do problema/necessidade, busca de informação, avaliação das alternativas, decisão de compra, ato da compra, avaliação póscompra. Esses autores também abordam que o processo de decisão do consumidor pode ser influenciado por determinantes pessoais e interpessoais. Os determinantes pessoais seriam: a percepção, as atitudes, a aprendizado e o conceito-próprio. Os determinantes interpessoais seriam: as influências culturais, sociais e as influências da família. Os determinantes pessoais e interpessoais influenciam as necessidades e desejos do consumidor.

Para que os consumidores sejam influenciados no seu processo decisório de compra por produtos ou serviços de empresas socialmente responsáveis, é necessário que eles saibam primeiramente o nível de responsabilidade social das empresas (MOHR et al., 2001). É importante, portanto, a divulgação dessas informações pelas organizações. Ao saberem dessas informações sobre a RSC, isso pode ou não afetar o comportamento do consumidor.

\section{ESTUDOS ANTERIORES FEITOS NO BRASIL SOBRE RESPONSABILIDADE SOCIAL NA ÓTICA DO CONSUMIDOR}

Sen e Bhattacharya (2001) disseram em seus estudos que há poucas pesquisas sobre a RSC na ótica do consumidor, isto é, há poucos artigos que falam da percepção dos consumidores a respeito do comportamento socialmente responsável das empresas. Auger ET al. (2003) também disseram que poucas pesquisas foram feitas para estudar a influência da RSC no comportamento do consumidor, logo há poucas evidências sobre o reflexo das questões sociais na decisão de compra.

Isso também pode ser visto no cenário brasileiro, pois ao fazer uma busca de artigos em congressos e periódicos, que retratam esse lado do consumidor, foram encontrados poucos estudos científicos. Esses estudos serão relatados a seguir. Urdan (2001) pesquisou dois pontos: qual a importância atribuída pelo consumidor ao comportamento ético da empresa e se o consumidor é propicio a recompensar o comportamento ético da empresa. Os pesquisados foram assinantes de linha telefônica fixa de Belo Horizonte e Contagem no ano de 1999. Foi extraída uma amostragem aleatória e enviada pelo correio o questionário com as perguntas. As conclusões foram que a importância atribuída pelo consumidor ao comportamento ético da empresa não parece causar a sua propensão a recompensá-la. Com isso, deve haver um incentivo por parte das empresas a mostrar ao consumidor a importância de eles recompensarem as organizações éticas.

Motta e Rossi (2003) pesquisaram se há influência do fator ecológico no comportamento de compra dos consumidores. Eles entrevistaram pessoas na cidade de São Paulo sobre a compra de detergentes e cremes dentais. Os resultados mostraram que, no momento da pesquisa, em 2003, os respondentes não levavam em conta o fator ecológico na hora da compra, porém como eles tinham o conhecimento sobre as questões ambientais e uma atitude positiva em 
relação a isso, futuramente isso pode ser uma fonte de vantagem competitiva das empresas. Motta e Rossi (2003) também identificaram que os consumidores não possuem informações suficientes sobre produtos ecologicamente corretos.

Mrtvi (2003) pesquisaram sobre a percepção dos consumidores em relação às ações socialmente responsáveis. 0 estudo foi feito sobre o setor de cosméticos e os pesquisados foram alunos de graduação de uma universidade pública do estado do Paraná. Os autores fizeram um mapa espacial com as marcas existentes de cosméticos diferenciando-as por atributo. As marcas Natura e Boticário são percebidas de forma muito diferenciada pelos consumidores, elas estão próximas no mapa espacial, e isso se deve principalmente em relação ao atributo de RSC. Evidenciou-se que esse é um atributo que diferencia a marca em relação às outras nesse setor. Porém, foi constatado que nem sempre os consumidores percebem com clareza os projetos sociais das empresas.

Analisando o mercado bancário, Volpon e Cruz (2004) procuraram identificar se as práticas de RSC neste setor são capazes de construir consumidores fiéis. Eles identificaram que os respondentes preferem ter conta em um banco que vise o lucro, mas com responsabilidade social e não em um banco que vise somente o lucro. Porém, eles identificaram que a maioria dos clientes dos bancos não trocaria de banco se soubesse que ele encerrou suas ações sociais, pois os clientes dão mais valor à amizade criada com o gerente, à localização das agências bancárias e às taxas praticadas pelo banco. Romaniello e Amâncio (2005) estudaram a percepção dos estudantes do curso de administração em relação à RSC, se esse tema constitui um fator de vantagem competitiva para a empresa. As evidências da pesquisa mostraram que o comportamento de compra dos estudantes de administração, que serão futuros gestores, é influenciado pela RSC das empresas. Essa conclusão foi obtida devido a $53 \%$ dos respondentes terem dito que seu comportamento de compra é influenciado pelas práticas socialmente responsáveis das empresas e 79,1\% disseram que puniriam as empresas com práticas que não são responsáveis nem éticas. A pesquisa foi feita através de um questionário aplicado a estudantes de uma universidade em Minas Gerais. Serpa (2005) realizou uma pesquisa com estudantes e executivos - futuros e atuais gestores do Rio de Janeiro - para identificar se eles consideram a ética e a RSC como fatores importantes para a eficácia da empresa. As evidências encontradas foram que há diferenças entre as percepções de futuros e atuais gestores, sendo que os atuais gestores valorizam mais a ética e a RSC para a eficácia da empresa do que os futuros gestores.

Posteriormente, Serpa e Avila (2006) pesquisaram os efeitos da RSC na percepção e na intenção de compra dos consumidores. Os autores buscaram identificar se os consumidores estão dispostos a pagar um pouco mais caro por um produto de uma empresa socialmente responsável ao invés de um produto mais barato de uma empresa que não pratica a RSC. 0 produto alvo da pesquisa foi a calça jeans, onde a calça jeans mais cara era da empresa socialmente responsável e a qualidade das calças era semelhante. 0 método utilizado foi um experimento, tendo um grupo experimental e um grupo de controle. 0 grupo experimental sabia as informações sobre qual empresa era socialmente responsável e o grupo de controle não. Todos os respondentes eram estudantes de graduação ou pós-graduação. Observou-se que houve uma diferença significativa entre as respostas do grupo experimental e do grupo de controle, sendo o grupo experimental aquele que percebe um benefício adicional ao produto da empresa que pratica a RSC e possuem uma intenção de compra positiva. Ou seja, os pesquisados mostraram que estão dispostos a pagar um pouco mais caro pelo produto da empresa socialmente responsável. 
Serpa e Avila (2006) expandiram o campo dessa pesquisa para também identificar se uma ação social com impacto direto na vida dos consumidores afeta mais a decisão de compra. Os resultados mostraram que ações sociais que têm impacto direto na vida dos consumidores influenciam mais positivamente as suas reações e intenções de compra do que a ação social que afeta indiretamente a vida dos consumidores.

Já a pesquisa de Castro et al. (2007) buscou identificar se há influência da RSC no comportamento do consumidor no Rio de Janeiro. Para isso, ele aplicou um questionário em dois grandes Shoppings Centers da cidade. Os resultados sugerem que os consumidores, de fato, se preocupam com as práticas de RSC das empresas, porém geralmente isso não afeta o seu comportamento de compra. Esse resultado é apontado devido à falta de informações que os consumidores possuem a respeito das ações socialmente responsáveis e porque na hora da compra eles valorizam o preço, a conveniência e a qualidade.

Dando continuidade às suas pesquisas, Serpa e Fourneau (2007) investigaram a percepção do consumidor a respeito do tema RSC. As autoras tinham como objetivo estudar o que os consumidores entendiam por RSC, se eles lembravam de empresas socialmente responsáveis, se eles buscavam informações sobre a postura das empresas e se essas informações influenciavam no seu comportamento de compra. Os resultados mostraram que os entrevistados consideram o tema recente no Brasil, e ainda têm certa dificuldade em definir a RSC, mas para eles o papel das empresas socialmente responsáveis é o de ajudar a resolver os problemas básicos do país, como educação e meio ambiente. Os entrevistados também lembraram somente de quatro empresas que atuam no Brasil e que praticam a RSC e disseram que há uma escassez de informação a respeito do tema no país. E em relação ao impacto das ações de RSC no comportamento do consumidor, os respondentes disseram que consideram os aspectos negativos na hora da compra, o que quer dizer que se a empresa é vista negativamente no mercado, se não é ética, eles não compram o produto dela, mas isso não quer dizer que se ela for socialmente responsável, eles irão comprar o produto da empresa. Os aspectos negativos influenciam mais que os positivos o comportamento de compra dos pesquisados.

\section{METODOLOGIA}

O presente artigo pode ser caracterizado como uma pesquisa descritiva, pois seu objetivo principal é descrever características de uma determinada população através da utilização de questionários para a coleta dos dados (GIL, 1987; REMENYI et al., 1998). A pesquisa também é um levantamento, já que se caracteriza pela interrogação direta das pessoas cujo comportamento se deseja conhecer (GIL, 1987). O levantamento é feito através da solicitação de informações ao público que será estudado sobre a questão central de pesquisa e em seguida são feitas análises quantitativas para serem feitas as considerações finais.

A primeira etapa da presente pesquisa foi realizar uma revisão da literatura para estudar e se aprofundar sobre o assunto. Foram estudados: o conceito de RSC, os temas que envolvem o comportamento do consumidor e as pesquisas existentes no Brasil sobre a responsabilidade social e a decisão de compra do cliente.

A segunda etapa consistiu na elaboração do questionário para a etapa da coleta de dados. 0 questionário foi feito baseado no questionário da pesquisa de Castro et al. (2007), porém foram feitas algumas alterações e inclusões de novas perguntas. 0 público alvo pesquisado foi diferente do público de Castrol et al. (2007). Enquanto eles pesquisaram o comportamento de consumidores no shopping, o presente estudo foi feito com estudantes de pós-graduação 
(mestrado acadêmico e profissional) e que também são consumidores.

O questionário consistiu em perguntas para medir a atitude dos consumidores em relação à RSC, medindo se eles julgam a compra socialmente responsável como sendo positiva ou negativa. Também consistiu em perguntas para medir o comportamento de compra dos entrevistados em relação a produtos socialmente responsáveis, para saber se há alguma variação entre atitude e comportamento, ou seja, o que eles pensam e como eles agem.

As opções de respostas a essas perguntas estavam em escala Likert de 5 pontos. 0 questionário também teve perguntas para saber se os consumidores estão satisfeitos com suas compras socialmente responsáveis e se eles estão satisfeitos com a quantidade de informações disponíveis sobre produtos ou serviços de empresas que são socialmente responsáveis. As respostas a essas perguntas consistiram em "Sim" ou "Não".

O questionário possuiu também uma pergunta onde os entrevistados tiveram que colocar em ordem de importância o que eles levam em consideração na hora da compra (reputação socialmente responsável, preço, conveniência, qualidade e marca). E ele também possuiu perguntas a respeito de dados demográficos como o sexo do entrevistado, a faixa etária e o estado civil.

Após a elaboração do questionário, que já foi testado previamente na pesquisa de Castro et al. (2007), a próxima etapa da pesquisa foi a coleta de dados. Foram entrevistados 45 estudantes do mestrado acadêmico e do mestrado profissional de Administração de uma universidade do Rio de Janeiro.

A próxima etapa consistiu no tratamento dos dados, que foram tratados através de análises utilizando o software SPSS. Foram realizadas no SPSS as Estatísticas da Distribuição de Freqüência, dentre elas a média, a mediana, a moda, a variância e o desvio padrão. (Malhotra, 2006).

A etapa seguinte foi a análise e interpretação dos dados tratados, que foram relatadas na área de Resultados e Discussão.

Na última etapa da pesquisa, foram feitas as considerações finais, foram tratadas as limitações do estudo e foram dadas sugestões para futuras pesquisas.

\section{RESULTADOS E DISCUSSÃO}

Foram entrevistados no total 45 estudantes de pós-graduação. Dos 45 estudantes, 18 foram do sexo feminino ( $40 \%$ do total) e 27 masculino (60\% do total). Do total, 29 eram solteiros (64\% do total) e 16 eram casados (36\% do total). Em relação à faixa etária, o gráfico 1 mostra sua distribuição.

Gráfico 1: Distribuição da Amostra por Faixa Etária

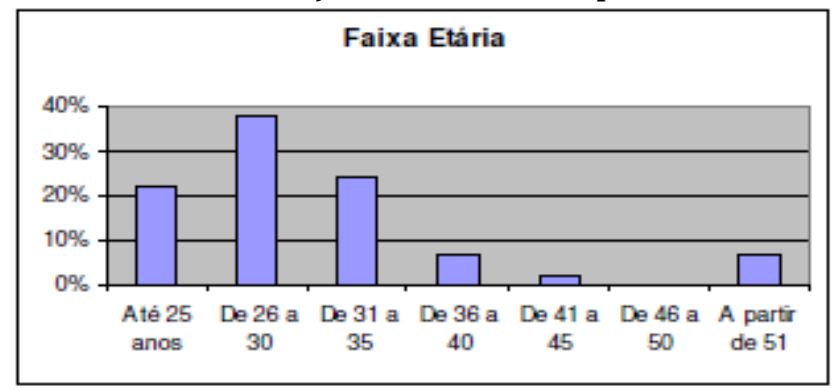




\section{Análise da atitude dos consumidores}

0 questionário foi dividido com perguntas referentes à atitude dos consumidores, perguntas referentes ao comportamento dos consumidores e perguntas referentes à ordenação por importância dos atributos que os consumidores entrevistados consideram na hora de decidir pela sua compra.

Analisando as questões referentes à atitude dos consumidores (questões de 1 a 3), pode-se observar que a maioria das respostas foi positiva. Portanto, a maioria das respostas mostrou que os entrevistados possuem uma atitude positiva em relação à compra de produtos socialmente responsável, eles possuem vontade de fazer esse tipo de compra e julgam esse tipo de compra como algo positivo.

A Tabela 1 mostra a média, a mediana, a moda, o desvio padrão e a variância das respostas (lembrando que as respostas foram em escala likert de 5 pontos, sendo 1 para "Discordo Totalmente" e assim por diante). A maioria dos entrevistados respondeu "Concordo em parte" ou "Concordo Totalmente" para as perguntas que ilustram a atitude dos consumidores para a compra socialmente responsável.

Portanto, os consumidores estão preocupados com a realização de ações socialmente responsáveis por parte das empresas, e com isso, eles valorizam a empresa que é socialmente responsável. É importante então, que as empresas procurem ter essas práticas e divulgá-las, pois os consumidores estão preocupados com esse tipo de ação.

Tabela 1: Estatísticas referentes às questões de atitude

\begin{tabular}{|l|r|r|r|r|r|}
\hline Questöes referentes à atitude & Média & Mediana & Moda & Desvio Padrão & Variância \\
\hline É importante comprar produtos de empresas socialmente responsáveis & 3,8667 & 4,0000 & 4,00 & 0,72614 & 0,527 \\
\hline $\begin{array}{l}\text { Eu fico realmente satisfeito em saber que a empresa da qual eu } \\
\text { compro os produtos, age socialmente responsável. }\end{array}$ & 4,5111 & 5,0000 & 5,00 & 0,75745 & 0,574 \\
\hline $\begin{array}{l}\text { Eu gostaria de comprar produtos de empresas socialmente } \\
\text { responsáveis, mas não possuo informações suficientes sobre as } \\
\text { empresas }\end{array}$ & & & & & \\
\hline
\end{tabular}

\section{Análise do comportamento dos consumidores}

A Tabela 2 apresenta a média, a mediana, a moda, o desvio padrão e a variância das respostas das questões referentes ao comportamento dos consumidores, ou seja, como eles se comportam atualmente em relação aos produtos de empresas socialmente responsáveis, como é feita a decisão de compra deles.

Analisando as questões referentes ao comportamento dos consumidores (questões de 4 a 12), pode-se observar que a maioria das respostas está nas escalas "Discordo em parte" e "Nem discordo, nem concordo", conforme descrito na Tabela 2.

Portanto, pode-se observar que a maioria das respostas mostra um comportamento negativo em relação à compra de produtos socialmente responsáveis, isto é, a maioria dos entrevistados não costuma comprar produtos de empresas que são socialmente responsáveis.

Apesar de eles terem uma atitude positiva em relação aos produtos de empresas que praticam a RSC, isso não é refletido no comportamento de compra dos consumidores. 
Tabela 2: Estatísticas referentes às questões de comportamento

\begin{tabular}{|c|c|c|c|c|c|}
\hline Questöes referentes ao comportamento & Média & Mediana & Moda & Desvio Padrāo & Variância \\
\hline Eu preferi comprar produtos de empresas socialmente responsáveis & 3,5333 & 3,0000 & 3,00 & 1,14018 & 1,300 \\
\hline $\begin{array}{l}\text { Eu comprei produtos mesmo sabendo que eles foram produzidos por } \\
\text { uma empresa socialmente irresponsável }\end{array}$ & 2,8667 & 3,0000 & 4,00 & 1,40777 & 1,982 \\
\hline $\begin{array}{l}\text { Eu preferi comprar produtos que fossem menos nocivos para o } \\
\text { ambiente e para outras pessoas }\end{array}$ & 4,0444 & 4,0000 & 4,00 & 0,90342 & 0,816 \\
\hline $\begin{array}{l}\text { Eu deixei de comprar um produto só porque ele foi produzido por } \\
\text { uma empresa socialmente irresponsável }\end{array}$ & 2,7556 & 3,0000 & 3,00 & 1,29957 & 1,689 \\
\hline $\begin{array}{l}\text { Eu já troquei uma das minhas marcas preferidas por razôes de cunho } \\
\text { social }\end{array}$ & 2,6000 & 3,0000 & 1,00 & 1,40454 & 1,973 \\
\hline $\begin{array}{l}\text { Eu paguei mais caro por um produto só porque ele foi produzido por } \\
\text { uma empresa socialmente responsável }\end{array}$ & 3,0000 & 3,0000 & 2,00 & 1,31426 & 1,727 \\
\hline $\begin{array}{l}\text { Eu fui a lojas mais distantes do que de costume só para comprar } \\
\text { produtos de uma empresa socialmente responsável }\end{array}$ & 2,3333 & 2,0000 & 1,00 & 1,2792 & 1,636 \\
\hline $\begin{array}{l}\text { Eu comprei um produto com qualidade inferior só porque ele foi } \\
\text { produzido por uma empresa socialmente responsável }\end{array}$ & 1,6444 & 1,0000 & 1,00 & 0,85694 & 0,734 \\
\hline $\begin{array}{l}\text { m geral, quando eu compro um produto/serviço, eu não me preocu } \\
\text { m saber se a empresa é socialmente responsável }\end{array}$ & 3,1778 & 3,0000 & 2,00 & 1,21148 & 1,468 \\
\hline
\end{tabular}

Porém, se as questões forem analisadas caso a caso, pode-se ver que algumas questões específicas mostram que o consumidor às vezes leva em conta o comportamento socialmente responsável das empresas na hora de comprar os produtos.

Na questão "Eu preferi comprar produtos de empresas socialmente responsáveis", a média foi 3,5333, mostrando que alguns consumidores já fizeram a opção de comprar produtos de empresas que praticam a RSC.

Outra questão que mostrou esse comportamento responsável foi a "Eu preferi comprar produtos que fossem menos nocivos para o ambiente e para outras pessoas". Nesta questão, a média foi de 4,0444 e a moda foi 4,00. Logo, a maioria respondeu "Concordo em parte", mostrando que os consumidores estão não só se preocupando com o meio ambiente como também estão procurando comprar produtos que agridam menos o meio ambiente. Esse resultado sobre o meio ambiente foi semelhante ao de Castro et al. (2007) mostrando que os consumidores estão mais ligados às questões ambientais. Essa informação pode ser útil para as empresas, pois se os consumidores estão valorizando produtos que não agridam o meio ambiente, as empresas precisam estar ligadas nisso que pode ser uma grande oportunidade para aquelas que estão cuidando do meio ambiente.

As outras questões tiveram suas respostas como "Discordo em parte" ou "Nem discordo, nem concordo", mostrando que a maioria das questões teve suas respostas negativas em relação ao comportamento socialmente responsável .

\section{Análise da ordem de importância dos atributos na hora de fazer a compra}

A questão 13 é referente à ordenação por importância de atributos que são considerados na hora de decidir pela compra. Os atributos foram: reputação socialmente responsável da empresa, preço, conveniência, qualidade e marca. A ordem de importância foi colocar 1 para o mais importante e 5 para o menos importante. Analisando as respostas dos entrevistados, pode-se observar que o atributo mais considerado na hora da compra foi a qualidade com média de 1,4889 e moda igual a 1 . 0 atributo considerado mais importante após a qualidade foi o preço com média de 2,6222 e moda igual a 2. 0 terceiro atributo mais importante foi a 
conveniência com média de 2,9333 e moda igual a 3. 0 quarto atributo mais importante foi a reputação socialmente responsável com média de 3,9778 e moda igual a 4 . 0 atributo considerado menos importante foi a marca com média de 3,9778 e moda igual a 5 . A Tabela 3 mostra esses dados.

Esses resultados da ordenação por escala de importância dos atributos na hora da compra foram semelhantes aos resultados de Castro et al. (2007), mostrando uma uniformidade entre a preferência dos atributos que influenciam a decisão de compra dos consumidores.

Tabela 3: Estatística referente à questão 13

\begin{tabular}{|c|c|c|c|c|c|c|}
\hline \multicolumn{7}{|c|}{ Statistics } \\
\hline & & $\begin{array}{l}\text { Reputaçao } \\
\text { Socialmente } \\
\text { Responsável }\end{array}$ & Preco & Conveniência & Qualidade & Marca \\
\hline \multirow[t]{2}{*}{$\mathrm{N}$} & Valid & 45 & 45 & 45 & 45 & 45 \\
\hline & Missing & 0 & 0 & 0 & 0 & 0 \\
\hline \multicolumn{2}{|c|}{ Mean } & 3,9778 & 2,6222 & 2,9333 & 1,4889 & 3,9778 \\
\hline \multicolumn{2}{|c|}{ Median } & 4,0000 & 2,0000 & 3,0000 & 1,0000 & 5,0000 \\
\hline \multicolumn{2}{|c|}{ Mode } & $4,00^{\mathrm{a}}$ & 2,00 & 3,00 & 1,00 & 5,00 \\
\hline \multicolumn{2}{|c|}{ Std. Deviation } & 1,09729 & ,96032 & 1,03133 & ,99138 & 1,27009 \\
\hline \multicolumn{2}{|c|}{ Variance } & 1,204 &, 922 & 1,064 & 983 & 1,613 \\
\hline
\end{tabular}

\section{Análise da satisfação do consumidor em relação ao seu comportamento socialmente responsável e em relação às informações disponíveis sobre RSC}

A Tabela 4 é referente às questões 14 e 15 que dizem respeito se o consumidor está satisfeito com o seu comportamento socialmente responsável e se o consumidor está satisfeito com as informações disponibilizadas pelas empresas sobre as ações socialmente responsáveis praticadas por elas. Essas questões podiam ser respondidas com "1-Sim" ou "2-Não".

Tabela 4: Estatísticas referentes às questões 14 e 15

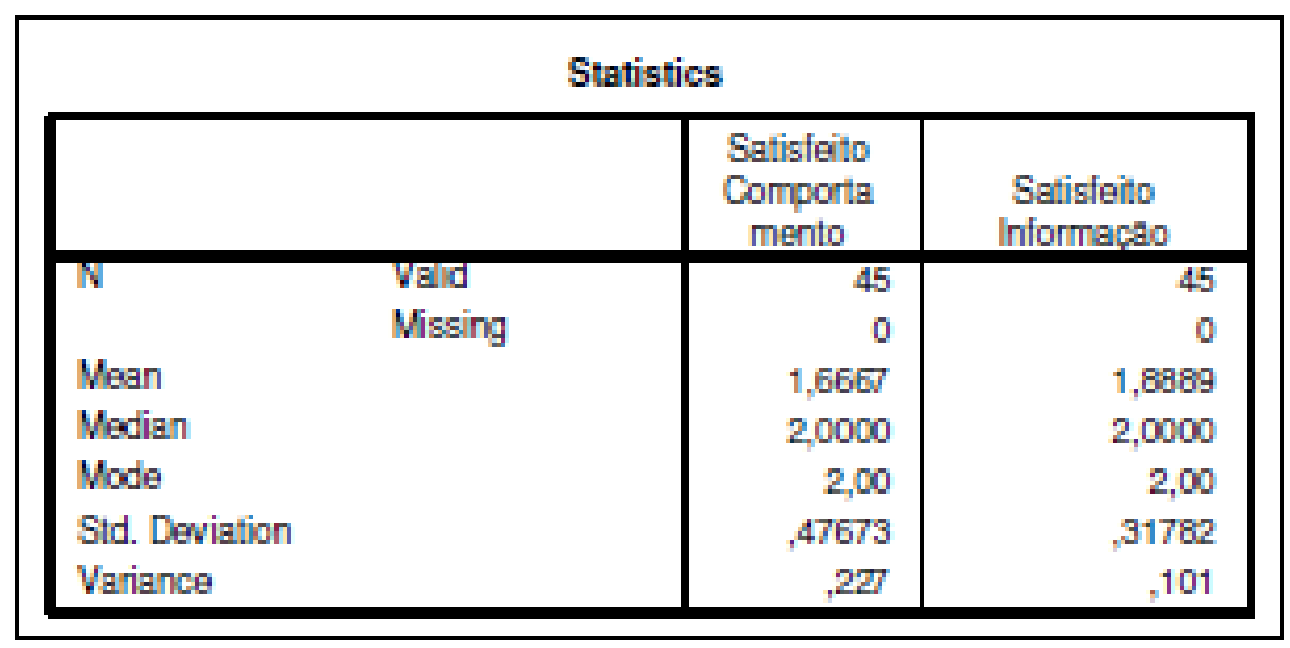

Analisando a Tabela 4, pode-se observar que a maior parte dos consumidores entrevistados não está satisfeito com seu comportamento de compra socialmente responsável, sendo uma média de 1,6667 e uma moda igual a 2. Ou seja, já foi observado que a atitude dos consumidores é positiva em relação à RSC e que isso ainda não se reflete no seu comportamento de forma consistente, mas que em algumas ocasiões, eles fazem esse tipo de 
compra. Mas pode-se observar, que os consumidores não estão satisfeitas com sua forma de comprar socialmente responsável, eles mostram uma preocupação em relação a isso.

Já em relação à questão de satisfação com as informações disponíveis sobre a RSC das empresas, a maioria dos consumidores entrevistados também não está satisfeito com a quantidade de informações, sendo uma média muito alta de 1,8889 , muito próxima a 2 . A moda foi igual a 2 .

Com isso, podemos observar que se as empresas fizessem uma divulgação maior de suas ações de RSC, teriam uma oportunidade de atrair consumidores, já que eles têm uma atitude positiva em relação a isso e estão insatisfeitos com seu modo de comprar socialmente responsável.

\section{Discussão}

Analisando os dados de um modo geral, pode-se observar que a maioria dos consumidores entrevistados possui uma atitude positiva em relação à compra de produtos socialmente responsáveis, mas na prática não se comporta desse jeito. E isso causa neles uma insatisfação em relação ao seu modo de comprar socialmente responsável. Além disso, atualmente, na hora de comprar, eles preferem produtos de qualidade primeiramente, seguido do preço, conveniência, reputação socialmente responsável e marca.

Essa má colocação da reputação socialmente responsável na ordem de importância dos consumidores entrevistados reflete o comportamento deles negativo em relação à compra socialmente responsável. As empresas que são socialmente responsáveis também precisam ter produtos de qualidade e com um bom preço, pois isso é fundamental na percepção dos consumidores.

Porém, os respondentes disseram que não estão satisfeitos com as informações disponíveis sobre os produtos de empresas socialmente responsáveis. Se observarmos que os consumidores possuem uma atitude positiva em relação à compra socialmente responsável, mas não fazem esse tipo de compra na prática e analisarmos essa situação com a resposta de que eles não estão satisfeitos com a quantidade de informações disponíveis sobre RSC das empresas, podemos evidenciar que é importante que eles tenham informações para poderem comprar produtos socialmente responsáveis.

Além disso, há indícios de que os consumidores às vezes fazem compras socialmente responsáveis. As respostas das questões "Eu preferi comprar produtos de empresas socialmente responsáveis" (média igual a 3,5333) e "Eu preferi comprar produtos que fossem menos nocivos para o ambiente e para outras pessoas" (média igual a 4,0444) mostram que alguns consumidores possuem práticas de comportamento socialmente responsáveis, principalmente ligadas ao meio ambiente. Caso as empresas disponibilizassem mais informações sobre suas ações de RSC, os consumidores, que possuem uma atitude positiva a isso, poderiam melhorar seu estilo comportamental de compras, passando a adquirir produtos de empresas socialmente responsáveis. Portanto, têm-se evidências de que o comportamento socialmente responsável das empresas poderia influenciar mais 0 comportamento de compra dos consumidores, caso as empresas disponibilizassem mais informações sobre a RSC. 


\section{CONSIDERAÇÕES FINAIS}

Muitos estudos têm sido feitos sobre a Responsabilidade Social, mas pouco se tem estudado sobre a ótica do consumidor, sobre se os consumidores estão dispostos a comprar produtos de empresas socialmente responsáveis, se eles se preocupam com esse tema que vem sendo muito discutido.

O presente estudo buscou complementar os poucos estudos já existentes sobre a RSC e mostrou resultados similares a alguns estudos anteriores.

De acordo com a pesquisa, os consumidores entrevistados, que foram alunos de mestrado em Administração, possuem uma atitude positiva em relação à compra de produtos de empresas socialmente responsáveis, ou seja, eles julgam esse tipo de compra como positiva. Porém, em relação ao seu comportamento, na prática observa-se que o consumo de produtos de empresas que praticam a RSC ainda é incipiente. Os consumidores ainda compram muito poucos produtos socialmente responsáveis. Mas há indícios de que os consumidores querem mudar seu comportamento. Houve uma resposta em que os consumidores mostraram que seu comportamento de compra em relação a produtos que respeitam o meio ambiente já está mudando. E, além disso, os consumidores se mostraram insatisfeitos em relação a seu comportamento de compra socialmente responsável. Por conseguinte, como eles estão insatisfeitos com seu comportamento e possuem uma atitude positiva em relação à compra de produtos de empresas socialmente responsáveis, mostram-se indícios de que eles querem comprar mais produtos socialmente responsáveis.

Como foi visto também, os consumidores acham que há poucas informações disponíveis sobre produtos socialmente responsáveis. Esse pode ser um motivo pela qual eles ainda não estão muito engajados nesse tipo de compra. Com isso, poderia ser interessante para as empresas, divulgarem mais esse tipo de informação. Elas poderiam colocar visivelmente nas embalagens de seus produtos, se o produto é "verde", pois há um interesse nos consumidores em relação a esse tipo de produto. As empresas poderiam também mostrar em suas propagandas suas ações socialmente responsáveis e mostrar como o consumidor pode contribuir para isso. Porém é importante que os produtos sejam de qualidade e tenham um bom preço, pois esses atributos ainda são muito importantes para os clientes.

Enfim, o estudo contribuiu para mostrar que o comportamento socialmente responsável das empresas afeta a atitude dos consumidores e está começando a afetar seu comportamento, porém de forma incipiente ainda. As empresas podem despender esforços para contribuir para a vontade de mudar o comportamento de compra socialmente responsável dos consumidores.

Como os estudos sobre comportamento do consumidor e RSC ainda são em poucas quantidades, é interessante haver mais estudos sobre isso, sendo então a sugestão para futuras pesquisas de estudar o comportamento dos consumidores em relação a RSC utilizando outros tipos de amostras e de regiões do Brasil, para nos aprofundarmos sobre esse tipo de comportamento.

Se tratando das limitações do estudo, ele foi feito com uma amostra pequena, de 45 estudando de mestrado, portanto há essa limitação referente ao tamanho da amostra. Outra limitação pode ser considerada que os respondentes são estudantes de uma só universidade, o que reduz a variedade do tipo de amostra. 


\section{REFERÊNCIAS BIBLIOGRÁFICAS}

ASHLEY, P. A. A Responsabilidade Social nos Negócios: um conceito em construção. In: ASHLEY, P. A. (org.). Ética e responsabilidade Social nos Negócios. São Paulo: Saraiva, 2002, p. 2-16.

AUGER, P.; BURKE, P.; DEVINNEY, T. M.; LOUVIERE, J. J. What Will Consumers Pay for Social Product Features? Journal of Business Ethics, v. 42, n. 3, 2003, p. 281-304.

BRONN, P. S.; VRIONI, A. B. Corporate social responsibility and cause-related marketing: an overview. International Journal of Advertising, v. 20, n. 2, 2001, p. 189-205.

CALIXTO, L. Responsabilidade Social Corporativa no Brasil: Um Estudo Longitudinal. In: Anais do XXXI ENANPAD. Rio de Janeiro: Anpad, 2007.

CARVALHO, A. P.; BARBIERI, J. C. Rótulos Ambientais Orgânicos Como Ferramenta de Acesso a Mercados de Países Desenvolvidos: Dois Estudos de Caso de Empreendimentos Agroindustriais Brasileiros. In: Anais do XXXI ENANPAD. Rio de Janeiro: Anpad, 2007.

CASTRO, F. A. R.; SIQUEIRA, J. R. M.; KUBRUSLY, L. S. A Influência da Responsabilidade Social Coorporativa no Comportamento do Consumidor na Cidade do Rio de Janeiro. In: Anais do XXXI ENANPAD. Rio de Janeiro: Anpad, 2007.

DUFlOTH, S. C.; BElluMAT, R. C. C. A Disseminação de Informações das Ações de Responsabilidade Social das Empresas. In: Anais do XXIX ENANPAD. Brasília: Anpad, 2005.

DRUCKER, P. Introdução à administração. 3 ed. São Paulo: Pioneira, 1995.

FARIA, A.; SAUERBRONN, F. F. A responsabilidade social é uma questão de estratégia? Uma abordagem crítica. Revista de Administração Pública, v. 42, n. 1, p. 7-33, 2008.

GIL, A. C. Como Elaborar Projetos de Pesquisa. São Paulo: Atlas, 1987.

Instituto Ethos de Empresas e Responsabilidade Social. Disponível em: www.ethos.org.br/ Acesso em Setembro 2007.

KOTLER, P. Administração de Marketing. São Paulo: Prentice Hall, 2000.

LOMBARDI, M. S.; BRITO, E. P. Z. Desenvolvimento sustentável como fator de competitividade. In: Anais do XXXI ENANPAD. Rio de Janeiro: Anpad, 2007.

MAlHotrA, N. K. Pesquisa de Marketing: Uma Orientação Aplicada. Porto Alegre: Bookman, 2006.

MCWILLIAMS, A.; SIEGEL, D. Corporate Social Responsibility: A Theory of the Firm Perspective. Academy of Management Review, v. 26, n. 1, 2001, p. 117-127.

MOHR, L. A.; WEBB, D. J. The Effects of Corporate Social Responsibility and Price on Consumer Responses. Journal of Consumer Affairs, v. 39, n. 1, 2005, p. 121-147.

MHOR, L. A.; WEBB, D. J.; HARRIS, K. E. Do Consumers Expect Companies to be Socially Responsible? The Impact of Corporate Social Responsibility on Buying Behavior. Journal of Consumer Affairs, v. 35, n. 1, 2001, p. 45-72. 
MOTTA, S. L. S.; ROSSI, G. B. A Influência do Fator Ecológico na Decisão de Compra de Bens de Conveniência. In: Anais do XXVII ENANPAD. Atibaia: Anpad, 2003.

MOTTA, S. L. S.; ROSSI, G. B. A Influência do Fator Ecológico na Decisão de Compra de Bens de Conveniência. Revista de Administração da Universidade de São Paulo, v. 38, n. 1, 2003, p. 46-57.

MRTVI, V. O. Percepção do Consumidor sobre Ações Corporativas Vinculadas ao Conceito de Responsabilidade Social: Um Estudo no Setor de Cosméticos. In: Anais do XXVII ENANPAD. Atibaia: Anpad, 2003.

PEREIRA, W. A.; CAMPOS FILHO, L. A. N. Configurações dos Elementos da Responsabilidade Social Corporativa Através da Proposição de um Modelo Conceitual Integrado. In: Anais do XXXI ENANPAD. Rio de Janeiro: Anpad, 2007.

PETER, J. P.; OLSON, C. J. Consumer Behavior and Marketing Strategy. McGraw Hill, United States, Seventh edition, 2005.

REMENYI, D.; WILliAMN, B.; MONEY, A.; SWARTZ, E. Doing Research in Business and Management: An Introduction to Process and Method. London: Sage Publications, 1998.

ROMANIELlO, M. M.; AMÂNCIO, R. Gestão Estratégica e a Responsabilidade Social Empresarial: Um Estudo sobre a Percepção dos Estudantes do Curso de Administração. Revista Eletrônica de Administração, v. 11, n. 3, 2005.

SCHOMMER, P. C.; ROCHA, F. C. C. As Três Ondas da Gestão Socialmente Responsável no Brasil: Dilemas, Oportunidades e Limites. In: Anais do XXXI ENANPAD. Rio de Janeiro: Anpad, 2007.

SCHROEDER, J. T.; SCHROEDER, I. Responsabilidade Social Corporativa: Limites e Possibilidades. RAE - Eletrônica, v. 3, n. 1, 2004.

SEN, S.; BHATTACHARYA, C. B. Does Doing Good Always Lead to Doing Better? Consumer Reactions to Corporate Social Responsibility. Journal of Marketing Research, v.38, n. 2, 2001 , p. $225-243$.

SEMENIK, R.; BAMOSSY, G. J. Princípios de Marketing. São Paulo: Makron, 1996.

SERPA, D. A. F. Ética e Responsabilidade Social Corporativa são Realmente Importantes? Um Estudo com Futuros e Atuais Gestores de Empresas. In: Anais do XXIX ENANPA $D$. Brasília: Anpad, 2005.

SERPA, D. A. F.; AVILA, M. G. Efeitos da Responsabilidade Social Corporativa no Benefício Percebido pelo Consumidor e na Intenção de Compra: Um Estudo Experimental. In: Anais do II Encontro de Marketing da ANPAD. Rio de Janeiro: Anpad, 2006.

SERPA, D. A. F.; AVILA, M. G. Efeitos da Responsabilidade Social Corporativa na Percepção do Consumidor sobre Preço e Valor: Um Estudo Experimental. In: Anais do XXX ENANPAD. Salvador: Anpad, 2006.

SERPA, D. A. F.; FOURNEAU, L. F. Responsabilidade Social Corporativa: uma Investigação sobre a Percepção do Consumidor. Revista de Administração Contemporânea, v. 11, n. 3, 2007. 
SERRA, F. A. R.; ALBERNAZ, A.; FERREIRA, M. P. A Responsabilidade Social como Fator na Estratégia Internacional: 0 Estudo do Caso Natura. Revista Eletrônica de Administração, v. 13, n. 4, 2007.

SOLOMON, M. R. Comportamento do Consumidor: Comprando, Possuindo e Sendo. Porto Alegre: Bookman, 2002.

SROUR, R. H. Poder, Cultura e Ética nas Organizações. 4 ed. Rio de Janeiro: Ed. Campus, 1998.

URDAN, A. T. Os consumidores recompensam o comportamento ético? Revista de Administração da Universidade de São Paulo, v. 36, n. 2, p. 6-15, 2001.

VOLPON, C. T.; CRUZ, E. P. A Importância da Responsabilidade Social na Fidelização dos Clientes: uma Investigação no Mercado Bancário. In: Anais do XXVIII ENANPAD. Curitiba: Anpad, 2004. 